Chronic Obstructive Pulmonary Diseases:

Journal of the COPD Foundation

\author{
Original Research
}

\title{
Veterans Airflow Obstruction Screening Questionnaire: A Survey to Identify Veterans with Airflow Obstruction
}

\author{
Folarin Sogbetun, $\mathrm{MD}^{1}$ William L. Eschenbacher, $\mathrm{MD}^{1,2}$ Jeffrey A. Welge, $\mathrm{PhD}^{3}$ Ralph J. Panos, $\mathrm{MD}^{1,2}$
}

\begin{abstract}
Chronic obstructive pulmonary disease (COPD) is a leading cause of morbidity and mortality within the Veterans Healthcare Administration (VHA) and is frequently under-diagnosed. We developed the Veterans Airflow Screening Questionnaire (VAFOSQ) to improve the identification of Veterans with airflow obstruction (AFO), the most commonly used criterion for the diagnosis of COPD. We created an initial survey with 78 variables that have been associated with AFO. A total of 825 patients in 3 primary care clinics performed spirometry after bronchodilator administration and completed the initial survey. Best sets regression was used to build a model that predicted AFO optimally. A total of 195 of 825 (23.3\%) patients had AFO and 7 items positively predicted AFO. When the questionnaire score was greater than 25, the VAFOSQ accurately identified AFO with an area under the receiver operating curve of 0.72 . In a prospective validation cohort of 376 participants, the positive predictive value was $32 \%$ and negative predictive value $81 \%$. The VAFOSQ is a reliable and valid instrument for the identification of veterans at risk for AFO who would benefit from further evaluation with spirometry and assessment for COPD. The VAFOSQ is straightforward to use and can be easily self-administered and self-scored enabling widespread application within the VHA.
\end{abstract}

\begin{abstract}
Abbreviations: chronic obstructive pulmonary disease, COPD; Veterans Healthcare Administration, VHA; Veterans Airflow Screening Questionnaire, VAFOSQ; airflow obstruction, AFO; forced expiratory volume in 1 second, FEV $_{\mathbf{1}}$; forced vital capacity, FVC; lower limit of normal, LLN; Third National Health and Nutrition Examination Survey, NHANES III; Veterans Administration Medical Center, VAMC; American Thoracic Society, ATS; receiver operating characteristics, ROC

Funding Support: This work was funded by the Veterans Healthcare Administration Specialty Care Services, Specialty Care Transformation Initiative.

Date of Acceptance: April 29, 2016

Citation: Sogbetun F, Eschenbacher WL, Welge JA, Panos RJ. Veterans airflow obstruction screening questionnaire: A survey to identify veterans with airflow obstruction. Chronic Obstr Pulm Dis (Miami). 2016;3(4):705-715. doi: http://dx.doi.org/10.15326/ jcopdf.3.4.2016.0128
\end{abstract}

\section{This article has an online supplement.}

1 Division of Pulmonary, Critical Care, and Sleep Medicine, Cincinnati, Veterans Affairs Medical Center Cincinnati, Ohio

2 Division of Pulmonary, Critical Care, and Sleep Medicine, Cincinnati, University of Cincinnati College of Medicine, Cincinnati, Ohio

3 Department of Psychiatry \& Behavioral Neuroscience, Department of Environmental Health (Division of Biostatistics and Bioinformatics), University of Cincinnati College of Medicine, Cincinnati, Ohio

\section{Address correspondence to:}

Ralph J. Panos, MD

Department of Medicine

Division of Pulmonary, Critical Care and Sleep Medicine,

Cincinnati Veteran Affairs Medical Center

3200 Vine Street,

Cincinnati, OH 45220

Phone: (513)475-6317

Email: ralph.panos@va.gov

\section{Keywords:}

chronic obstructive pulmonary disease; COPD; screening questionnaire 


\section{Introduction}

Chronic obstructive pulmonary disease (COPD) is an important cause of morbidity and mortality both in the United States and worldwide. ${ }^{1-3}$ COPD is an underrecognized condition and diagnosis frequently does not occur until lung function is significantly diminished. ${ }^{4}$ Increasing evidence suggests that early detection and intervention are the best methods of reducing the burden of COPD and improving the quality of life of patients with COPD. ${ }^{5-8}$ Spirometry is the best method to diagnose airflow obstruction (AFO) and a forced expiratory volume in 1 second $\left(F E V_{1}\right)$ to forced vital capacity (FVC) ratio less than either 0.7 or the lower limit of normal (LLN) are the usual thresholds for the presence of AFO.

The Third National Health and Nutrition Examination Survey (NHANES III) estimated the prevalence of COPD at $6.8 \%$ to $8.5 \%$ within the general U.S. population and a more recent Centers for Disease Control and Prevention questionnaire-based survey reported 6.3\% of the population had been diagnosed with COPD., ${ }^{9,10}$ Among veterans hospitalized in the VHA from 1997 to 2001, COPD was the fourth most common discharge diagnosis; approximately one third of all VHA patients and one sixth of all VHA inpatients had a diagnosis of COPD. ${ }^{11}$ The prevalence of COPD in the VHA population is $33 \%-43 \%$ and $C O P D$ is also underdiagnosed in this population. ${ }^{12}$

Recently, COPD diagnosis has been improved by the development of reliable screening questionnaires that identify individuals likely to have AFO and who are candidates for further evaluation with spirometry and assessment for COPD. ${ }^{13}$ These questionnaires have, however, been developed and validated in samples of the general population or among those with pulmonary disorders. ${ }^{14-16}$ The VHA patient population is significantly different from the general population - it is mostly male and older with a higher prevalence of both ever smoking and AFO. ${ }^{12,17}$ Screening questionnaires designed and validated in the general population tend to be less accurate in the VHA population and there is a need for a VHA-specific COPD screening questionnaire to identify patients who would benefit from further evaluation with spirometry. Further, all questionnaires to date have used a fixed ratio threshold $\left(F E V_{1} / F V C<0.7\right)$ for the diagnosis of $A F O$ rather than LLN $\left(F E V_{1} / F V C<L L N\right)$.

As part of a VHA quality improvement project aimed at developing a patient-centered model for the management of COPD, we developed an AFO screening instrument to identify veterans with an increased risk for AFO and who might benefit from spirometry and assessment for COPD.

\section{Materials and Methods \\ Questionnaire Construction}

Initial questionnaire development began with a synthesis of the literature reviewing common symptoms and historical factors in patients with AFO and COPD. These variables were organized into 5 conceptual domains: (1)functional impairment, (2) phlegm production, (3)history of upper respiratory tract infections, (4)history of chest congestion, cough and wheezing, and (5)smoking exposure and history. Starting with the 5 domains, our working group (2 pulmonologists and an internist) developed questions based upon the presence, frequency, duration, and quality of COPD symptoms. The initial questionnaire also included a review of patient-identified, previously diagnosed medical conditions, and the respondent's age and sex. The initial questionnaire included 78 Likert style questions and was tested in the Cincinnati Veterans Administration Medical Center (VAMC) pulmonary clinic to ensure that patients could easily understand the questions; any ambiguous questions were revised and retested. The 78 item initial questionnaire is included in the online supplement, Appendix A.

\section{Data Collection}

Three licensed practical nurses and an internist underwent spirometry training and performed all spirometry testing. For approximately 6 months, all patients at 3 Cincinnati VAMC primary care clinics with a previously scheduled office visit were asked to participate in the study. A total of 887 patients completed the 78 item questionnaire; spirometry was performed before and 10 minutes after albuterol administration via a metered-dose inhaler and a spacer according to American Thoracic Society (ATS) standards. ${ }^{18}$ AFO was defined as post-bronchodilator $\mathrm{FEV}_{1} / \mathrm{FVC}<\mathrm{LLN}$ calculated from the NHANES III data. ${ }^{19}$ We selected the LLN as the threshold for the definition of AFO because it controls for age-related changes in the $\mathrm{FEV}_{1} /$ FVC which are not accounted for by the 0.7 fixed ratio threshold. ${ }^{20,21}$ Spirometry tracings were reviewed by a pulmonologist to ensure adherence with ATS 
standards. ${ }^{18}$ Only patients with spirometry tracings meeting ATS criteria were included in the analysis.

\section{Statistical Analysis}

We divided the complete sample ( $\mathrm{N}=887)$ into a model building subset $(\mathrm{n}=600)$ and a retrospective validation subset $(\mathrm{n}=287)$. Using best-subsets regression, we identified the 10 best fitting combinations of predictors (from the initial set of 78 questions) for model sizes of 5 to 10 variables (an instrument with $>10$ questions was considered too lengthy). We then assessed which variables consistently appeared in the best fitting models (i.e., the proportion of times each variable appeared in the top models). This process identified 7 questions that showed the most robust association with AFO and we verified that combinations of these variables formed one of the best 7-variable models (this step was necessary to ensure that highly collinear variables with strong univariate associations with the outcome were not used together but rather that each variable contributed independent predictive power). To create a simple scoring algorithm based on summing Likerttype scores (ranging from 0 to 3), we iteratively tested various weightings of these variables to find a scoring that retained as much of the predictive power of the original regression equation as possible. The resulting screening instrument was scored prospectively in the validation sample to give an unbiased independent estimate of its predictive power in future applications in similar VHA populations.

\section{Prospective Validation Testing}

The 7 item Veterans AFO Screening Questionnaire (VAFOSQ) was validated prospectively in 3 VHA primary care clinics. For a period of approximately 3 months, all patients with a previously scheduled office visit were recruited for study participation and 380 patients completed the questionnaire. Spirometry was performed before and 10 minutes after albuterol administration via a metered-dose inhaler and a spacer according to ATS standards. ${ }^{18}$

\section{Test-Retest Study}

A subset of participants in the validation cohort were given the VAFOSQ and a stamped self-addressed envelope $(n=45)$. They were asked to complete the VAFOSQ 2 weeks after participation in the validation study and return the questionnaire by mail for testretest reliability analysis. A total of 18 patients returned the questionnaires.

\section{Results}

\section{Demographics and Spirometry}

A total of 887 patients completed the initial 78 item questionnaire; 62 (7.0\%) were not included in the analysis due to incomplete questionnaires $(n=35)$ or for incomplete spirometry or spirometry that did not meet ATS standards ( $\mathrm{n}=27)$. Of the 825 participants included in the analysis, the mean age was 62.9 years (SD 11.1, range 21-93) and 195 (23.6\%) had AFO based upon $\mathrm{FEV}_{1} / \mathrm{FVC}<\mathrm{LLN}$. A majority, 776 (94.1\%), were male. A total of 76 patients (9.2\%) had self-reported emphysema and 86 (10.4\%) had self-reported chronic bronchitis. Patients with AFO were likely to be older with a history of smoking. Table 1 presents participants' demographic and clinical characteristics.

Spirometry data are presented in Table 2. A total of 630 patients (76.4\%) had no AFO; 20 (2.4\%) had mild AFO, 120 (14.5\%) had moderate AFO, 42 (5.1\%) had severe AFO, and 13 (1.6\%) had very severe AFO based upon $\mathrm{FEV}_{1}$ \%predicted. ${ }^{20}$ Bronchodilator responsiveness ( $\geq 12 \%$ increase over baseline and $\geq 200 \mathrm{ml}$ ) was present in 38 (19.5\%) patients with AFO. In patients without AFO, bronchodilator responsiveness occurred in 11 $(1.7 \%)$.

\section{Initial Scoring}

Item level missing data were mostly less than $4 \%$ except for a few items listed in Table 3. Overall missing items accounted for $1.3 \%$ of the initial 78 item questionnaire.

Table 4 shows the results of applying the final AFO screening questionnaire to the original dataset. The average score was 25.4 for patients with AFO and 20.9 for those without AFO. The mean VAFOSQ score increased as the severity of AFO worsened (Table 4). The score was 22.3 in patients with mild COPD, 25.1 in patients with moderate COPD, 26.3 in patients with severe COPD and 30.0 in patients with very severe COPD. Figure 1 shows the final screening questionnaire; within each response box is a shaded number that is the weighted score of that response.

Receiver operating characteristics ( $\mathrm{ROC}$ ) analysis was conducted to evaluate the VAFOSQ score in screening for AFO. ${ }^{22}$ Table 5 shows the changes in sensitivity, specificity, positive predictive value, negative predictive value, and odds ratio of different total score thresholds. Lower cut-offs are associated with a higher sensitivity 


\section{Table 1. Patient Demographics}

\begin{tabular}{|c|c|c|c|c|}
\hline & $\begin{array}{c}\text { Airways Obstruction } \\
\text { (FEV1/FVC < LLN) }\end{array}$ & $\%$ & $\begin{array}{c}\text { No Airways Obstruction } \\
\text { (FEV//FVC > LLN) }\end{array}$ & $\%$ \\
\hline $\mathbf{n}$ & 195 & $23.6 \%$ & 630 & $76.4 \%$ \\
\hline Age mean+SD (range) & $64.8+10.6(27-93)$ & - & $62.3+11.2(21-92)$ & - \\
\hline Male & 186 & $22.50 \%$ & 590 & $71.50 \%$ \\
\hline
\end{tabular}

Self-reported Chronic Conditions

\begin{tabular}{|c|c|c|c|c|}
\hline COPD & 89 & $10.80 \%$ & 74 & $9.00 \%$ \\
\hline Asthma & 49 & $5.90 \%$ & 87 & $10.50 \%$ \\
\hline Emphysema & 48 & $5.80 \%$ & 28 & $3.40 \%$ \\
\hline Chronic Bronchitis & 33 & $4.00 \%$ & 53 & $6.40 \%$ \\
\hline Lung Cancer & 5 & $0.60 \%$ & 3 & $0.40 \%$ \\
\hline Sleep Apnea & 21 & $2.50 \%$ & 129 & $15.60 \%$ \\
\hline Heart Attack & 26 & $3.20 \%$ & 79 & $9.60 \%$ \\
\hline Stroke & 13 & $1.60 \%$ & 51 & $6.20 \%$ \\
\hline Heart Failure & 6 & $0.70 \%$ & 28 & $3.40 \%$ \\
\hline Anemia & 3 & $0.40 \%$ & 35 & $4.20 \%$ \\
\hline Pulmonary Embolism & 3 & $0.40 \%$ & 3 & $0.40 \%$ \\
\hline DVT & 12 & $1.50 \%$ & 25 & $3.00 \%$ \\
\hline Hypertension & 115 & $13.90 \%$ & 391 & $47.40 \%$ \\
\hline Osteoporosis & 5 & $0.60 \%$ & 18 & $2.20 \%$ \\
\hline Depression & 60 & $7.30 \%$ & 193 & $23.40 \%$ \\
\hline Anxiety & 37 & $4.50 \%$ & 146 & $17.70 \%$ \\
\hline Weight Loss & 15 & $1.80 \%$ & 47 & $5.70 \%$ \\
\hline
\end{tabular}

\section{Smoking History}

\begin{tabular}{l|r|r|r|r}
\hline Never Smoked & 5 & $1.00 \%$ & 101 & $12.20 \%$ \\
\hline Former Smoker & 84 & $10.20 \%$ & 308 & $37.30 \%$ \\
\hline Current Smoker & 106 & $12.80 \%$ & 221 & $26.80 \%$ \\
\hline
\end{tabular}

\section{Passive Smoke Exposure}

\begin{tabular}{l|r|r|r|r}
\hline Mother Smoked & 99 & $12.00 \%$ & 281 & $34.10 \%$ \\
\hline Father Smoked & 152 & $18.40 \%$ & 446 & $54.10 \%$ \\
\hline Partner Smoked & 160 & $19.40 \%$ & 461 & $55.90 \%$ \\
\hline Prescribed Inhaler & & & & \\
\hline
\end{tabular}

Percentages are the proportion of the entire study population $n=825 . \mathrm{FEV}_{1}$ : forced expiratory volume in 1 second;

FVC: forced vital capacity; LLN: lower limit of normal; COPD: chronic obstructive pulmonary disease;

$\mathrm{SD}$ : standard deviation; DVT: deep venous thrombosis

and lower specificity while higher scores provide a lower sensitivity and higher specificity. A total score threshold of 25 provided an optimal balance between sensitivity and specificity as well as high correct classification rates for AFO. Figure 2 shows the ROC curve and, at the selected threshold of 25, VAFOSQ sensitivity was
$59.9 \%$ and specificity was $69.8 \%$ with an area under the curve of 0.72 .

\section{Prospective Validation and Test-Retest Reliability}

Of the 383 participants in the validation study, 376 completed acceptable spirometry testing. Based 


\section{Table 2. Spirometry}

\begin{tabular}{|c|c|c|c|c|c|c|}
\hline \multirow{2}{*}{ Spirometry } & \multicolumn{2}{|c|}{ All } & \multicolumn{2}{|c|}{ +AFO } & \multicolumn{2}{|c|}{-AFO } \\
\hline & Pre-BD & Post-BD & Pre-BD & Post-BD & Pre-BD & Post-BD \\
\hline $\begin{array}{l}\text { FEV }_{1} \text { mean+SD } \\
\text { (range) liters }\end{array}$ & $\begin{array}{r}2.53+0.84 \\
(0.34-4.75)\end{array}$ & $\begin{array}{r}2.63+0.82 \\
(0.50-4.83)\end{array}$ & $\begin{array}{r}1.7+0.7 \\
(0.34-4.29)\end{array}$ & $\begin{array}{r}1.9+0.7 \\
(0.50-4.48)\end{array}$ & $\begin{array}{r}2.8+0.7 \\
(0.78-4.75)\end{array}$ & $\begin{array}{r}2.9+0.7 \\
(0.84-4.83)\end{array}$ \\
\hline $\begin{array}{l}\text { FEV }_{1} \% \text { Predicted } \\
\text { mean+SD (range) }\end{array}$ & $\begin{array}{r}77.89+22.85 \\
(11-175)\end{array}$ & $\begin{array}{r}81.51+21.93 \\
(17-168)\end{array}$ & $\begin{array}{l}55.0+18.4 \\
(11.7-100)\end{array}$ & $\begin{array}{r}59.46+17.63 \\
(17-104)\end{array}$ & $\begin{array}{r}85.7+18.9 \\
(30.2-174.9)\end{array}$ & $\begin{array}{r}88.3+18.2 \\
(38-169)\end{array}$ \\
\hline $\begin{array}{l}\text { FVC mean+SD } \\
\text { (range) liters }\end{array}$ & $\begin{array}{r}3.55+0.91 \\
(0.99-6.78)\end{array}$ & $\begin{array}{r}3.63+0.88 \\
(1.23-6.76)\end{array}$ & $\begin{array}{r}3.2+0.9 \\
(0.99-6.78)\end{array}$ & $\begin{array}{r}3.4+0.9 \\
(1.39-6.76)\end{array}$ & $\begin{array}{r}3.7+0.9 \\
(1.23-6.34)\end{array}$ & $\begin{array}{r}3.7+0.9 \\
(1.23-6.33)\end{array}$ \\
\hline $\begin{array}{l}\text { FVC \% Predicted } \\
\text { mean+SD (range) }\end{array}$ & $\begin{array}{r}82.82+17.90 \\
(26-148)\end{array}$ & $\begin{array}{r}85.25+16.95 \\
(30-142)\end{array}$ & $\begin{array}{r}75.0+18.1 \\
(26-116)\end{array}$ & $\begin{array}{r}80.95+16.92 \\
(30-116)\end{array}$ & $\begin{array}{r}85.2+17.1 \\
(32-148)\end{array}$ & $\begin{array}{r}86.6+16.7 \\
(36-142)\end{array}$ \\
\hline $\begin{array}{l}\mathrm{FEV}_{1} / \mathrm{FVC} \\
\text { mean+SD (range) }\end{array}$ & $\begin{array}{r}0.70+0.12 \\
(.24-.92)\end{array}$ & $\begin{array}{r}0.72+0.12 \\
(0.26-0.93)\end{array}$ & $\begin{array}{r}0.53+.10 \\
(0.24-0.84)\end{array}$ & $\begin{array}{r}0.54+0.10 \\
(0.26-0.87)\end{array}$ & $\begin{array}{r}0.76+0.07 \\
(0.51-0.92)\end{array}$ & $\begin{array}{r}0.77+0.07 \\
(0.6-0.93)\end{array}$ \\
\hline
\end{tabular}

AFO: airflow obstruction; $\mathrm{BD}$ : bronchodilator; $\mathrm{FEV}_{1}$ : forced expiratory volume in 1 second; FVC: forced vital capacity; SD: standard deviation

\section{Table 3. Survey Items With the Highest Missing Response Rates}

\begin{tabular}{l|l} 
Questionnaire Item & $\begin{array}{c}\text { Missing } \\
\text { Response } \\
\text { Rate }\end{array}$ \\
\hline How often do your symptoms worsen? & $4.1 \%$ \\
\hline Years lived with smoker & $4.2 \%$ \\
\hline Packs smoked per day & $5.2 \%$ \\
\hline How many years have you been coughing? & $6.0 \%$ \\
\hline How many years have you had phlegm? & $6.8 \%$ \\
\hline How old where you when you started wheezing? & $7.2 \%$ \\
\hline How many years have you been wheezing? & $8.6 \%$ \\
\hline \hline
\end{tabular}

upon a LLN threshold, 102 (27.1\%) had AFO and 274 (72.2\%) did not. The mean post-bronchodilator FEV 1 was $2.69+0.87$ liters and the mean FVC was $3.81+1.03$ liters. A total of 338 (89.9\%) patients had smoked more than 100 cigarettes in their lifetime and 97 (25.8\%) had a prior history of COPD. In this prospective validation cohort, the sensitivity of the VAFOSQ for AFO was $72 \%$ and the specificity was $44 \%$. The positive predictive value was $32 \%$ and the negative predictive value was $81 \%$.
A subset of the validation cohort completed the screening questionnaire, repeated it 2 weeks later, and returned the second response by mail. The average initial score was 26.5 and the average re-test score was 26.9. The overall correlation coefficient was 0.6.

\section{Discussion}

We developed a brief, easy to complete AFO screening survey based upon patient reported information and validated the questionnaire in VHA primary care clinics. The survey was designed for ease of administration and can be completed by patients across a range of literary skills. The final VAFOSQ can be self-administered, increasing the reach and ease of screening. The VAFOSQ is administered and completed quickly and can be incorporated as part of routine screening at a primary care clinic visit. The questionnaire includes 7 items: (1)smoking history, (2)previously diagnosed history of anxiety, (3)chest tightness, (4)frequency of breathing problems, (5)frequency of frustration, (6)cough, and (7) history of noisy breathing. Because, unlike other COPD screening questionnaires, we utilized the LLN (which is age dependent) instead of a fixed ratio as the $\mathrm{FEV}_{1} / \mathrm{FVC}$ threshold for AFO, age was not a significant variable and was excluded from the final questionnaire. Some of 


\section{Table 4. Comparison of Veterans Airflow Screening Questionnaire Scores in Patient Subsets}

\begin{tabular}{l|c|c}
\hline Patient Population & N & $\begin{array}{c}\text { VAFOSQ Score } \\
\text { (mean+SD) }\end{array}$ \\
\hline Total Population & 825 & $21.96+/-8.08$ \\
\hline No AFO: $\mathrm{FEV}_{1} / \mathrm{FVC}>\mathrm{LLN}$ & 630 & $20.9+8.5$ \\
\hline AFO:FEV $/ \mathrm{FVC}<\mathrm{LLN}$ & 195 & $25.4+5.3$ \\
\hline
\end{tabular}

\section{AFO Severity}

\begin{tabular}{lr|l}
\hline No AFO & 630 & $20.9+8.5$ \\
\hline Mild AFO:FEV $1>=80 \%$ Predicted & 20 & $22.3+6.1$ \\
\hline Moderate AFO:FEV $1<80 \%$ predicted & 120 & $25.1+4.8$ \\
\hline Severe/Very Severe $\mathrm{AFO}: \mathrm{FEV}_{1}<50 \%$ predicted & 55 & $27.2+5.2$ \\
\hline
\end{tabular}

\section{Chronic Conditions}

\begin{tabular}{l|r|l}
\hline COPD & 163 & $26.6+5.4$ \\
\hline Emphysema & 76 & $27.3+4.8$ \\
\hline Chronic Bronchitis & 86 & $24.8+7.0$ \\
\hline
\end{tabular}

\section{Gender}

\begin{tabular}{l|r|c}
\hline Male & 776 & $21.98+8.0$ \\
\hline Female & 49 & $21.67+8.8$ \\
\hline
\end{tabular}

\section{Prescribed inhaler}

\begin{tabular}{l|l|l}
\hline Yes & 382 & $23.9+7.7$ \\
\hline No & 419 & $20.1+8.1$ \\
\hline
\end{tabular}

VAFOSQ: Veterans Airflow Obstruction Screening Questionnaire; SD: standard deviation; AFO: airflow obstruction; $\mathrm{FEV}_{1}$ : forced expiratory volume in 1 second; FVC: forced vital capacity; COPD: chronic obstructive pulmonary disease the selected variables (history of anxiety) have not been included in previous COPD screening questionnaires; however, the combination of the 7 variables results in a highly predictive model. A weighted-sum of these items creates a score that differentiates between patients with and without AFO and the score magnitude correlates with COPD severity.

The VAFOSQ scores correlate well with the presence of AFO and higher VAFOSQ scores indicate an increased likelihood of AFO. The mean VAFOSQ score is lowest in patients with no $\mathrm{AFO}$ and it increases gradually from mild to moderate to severe AFO. It is highest in patients with very severe AFO. Lower VAFOSQ threshold scores increase the detection of patients with AFO (higher sensitivity) but are also positive in an increased number of patients with no AFO (lower specificity). A threshold of 25 results in a sensitivity of $59.9 \%$, a specificity of $69.8 \%$ and an area under the ROC curve of 0.72 . Other potential applications of this survey in different populations may require a higher or lower cutoff for increased sensitivity or increased specificity.

Patients with COPD often fail to seek medical care for a variety of reasons; their symptoms progress gradually and they limit their activities to cope with worsening respiratory impairment. They do not realize their limitations are abnormal and that their symptoms can be improved. ${ }^{23}$ COPD is underdiagnosed by $25 \%-50 \%$ in Italy. ${ }^{24}$ In Spain, only $60 \%$ of patients with respiratory symptoms are seen by a provider and only $45 \%$ of them undergo spirometry testing. ${ }^{25}$ Up to $80 \%$ of all individuals with AFO and half with severe AFO are not diagnosed. ${ }^{26}$ Similarly, within the VHA, approximately two-thirds of individuals with AFO are not diagnosed with COPD. ${ }^{12}$ Thus, COPD remains an under-recognized and underdiagnosed disease despite the ready availability of spirometry for measurement of AFO. ${ }^{4,27}$ Often, a COPD diagnosis is delayed until the condition is advanced. ${ }^{28}$ Spirometry is a reliable, simple, noninvasive, safe, and non-expensive procedure but it continues to be underutilized in the diagnosis of COPD because universal AFO screening is not recommended. ${ }^{20,27,29}$ COPD screening questionnaires have proven to be useful in selecting patients for further evaluation with spirometry and use of these questionnaires encourages targeted deployment of health care resources. ${ }^{13-16}$ Screening questionnaires that can be self-administered may aid in earlier COPD diagnosis which may improve clinical outcomes. ${ }^{28-30}$

Among 342 patients hospitalized for the first time for a COPD exacerbation, 34\% did not have a prior diagnosis of COPD and were not treated previously with any respiratory medication. ${ }^{31}$ More of these previously undiagnosed patients quit smoking in the 3 months after hospitalization than did the diagnosed patients, $16 \%$, versus $5 \%,{ }^{31}$ respectively. Patients diagnosed with AFO are more likely to quit smoking. ${ }^{32-34}$ Patients diagnosed with COPD who quit smoking experience 
Figure 1. Veterans Airflow Screening Questionnaire

\section{VETERANS AIRFLOW OBSTRUCTION SCREENING QUESTIONNAIRE}

This questionnaire screens for chronic obstructive pulmonary disease (COPD) which includes disorders such as chronic bronchitis and emphysema. Please mark an $X$ in the response box ( $\square$ ) that corresponds to your best answer to each question.

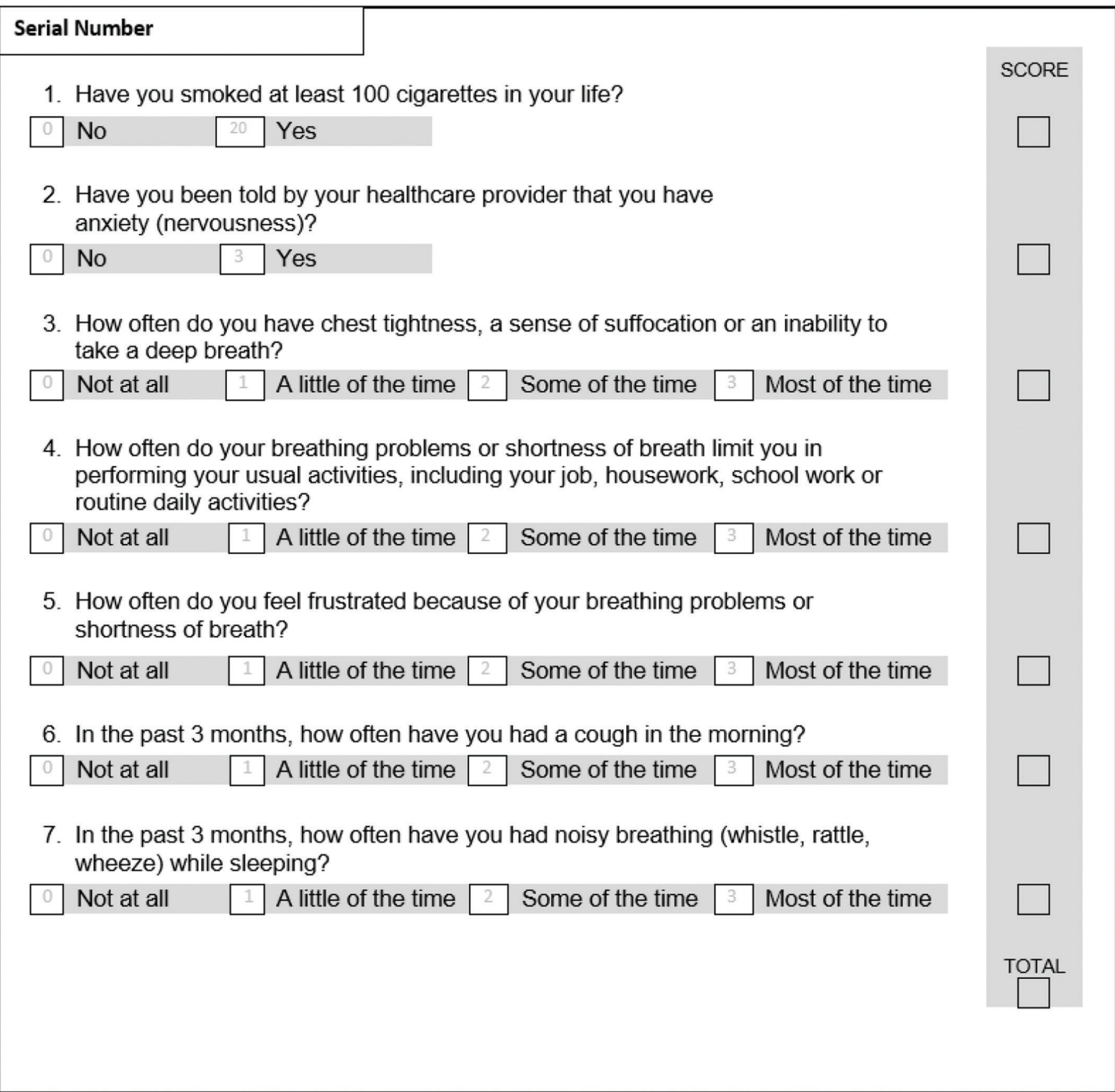

Please review the results of this survey with your primary care provider who may order further testing such as pulmonary function or radiology tests after discussion with you.

The Veterans Airflow Screening Questionnaire (VAFOSQ) is an easy to complete, self-administered survey. The respondent places an X in the box corresponding to his/her answer to each question. Beneath each box is a numerical score which is written in the box on the far right of each line. These scores are summed to obtain the total score in the bottom right hand box. A score of 25 or greater predicts the presence of airflow obstruction.

an improvement in $\mathrm{FEV}_{1}$ in the first year after quitting and the subsequent rate of $\mathrm{FEV}_{1}$ decline is half the rate of continuing smokers and comparable to that of never-smokers. ${ }^{34,35}$ Thus, earlier diagnosis of AFO improves smoking cessation preserving lung function and improving quality of life..$^{5}$

Primary care physicians' assessments of their patients' COPD severity are inaccurate for $70 \%$ of patients with 
Table 5. Performance of Different Veterans
Airflow Screening Questionnaire Total Score
Thresholds in the Development Cohort

Total Odds Sensitivity Specificity PPV Score Ratio

\begin{tabular}{l|l|l|l|l|l|l}
\hline 20 & 7.3 & $97.4 \%$ & $16.0 \%$ & $26.4 \%$ & $95.3 \%$ & $33.9 \%$ \\
\hline 21 & 5.3 & $92.3 \%$ & $30.6 \%$ & $29.2 \%$ & $92.8 \%$ & $43.9 \%$ \\
\hline 22 & 3.4 & $82.0 \%$ & $43.1 \%$ & $30.8 \%$ & $88.6 \%$ & $50.5 \%$ \\
\hline 23 & 3.2 & $74.7 \%$ & $52.3 \%$ & $32.6 \%$ & $87.0 \%$ & $55.6 \%$ \\
\hline 24 & 3.3 & $66.3 \%$ & $62.8 \%$ & $35.4 \%$ & $85.9 \%$ & $61.7 \%$ \\
\hline 25 & 3.5 & $59.9 \%$ & $69.8 \%$ & $37.7 \%$ & $85.1 \%$ & $65.6 \%$ \\
\hline 26 & 3.0 & $49.5 \%$ & $75.5 \%$ & $38.2 \%$ & $83.0 \%$ & $67.4 \%$ \\
\hline 27 & 2.6 & $40.3 \%$ & $79.5 \%$ & $37.4 \%$ & $81.4 \%$ & $68.4 \%$ \\
\hline 28 & 2.4 & $33.0 \%$ & $82.8 \%$ & $36.8 \%$ & $80.3 \%$ & $69.0 \%$ \\
\hline 29 & 2.0 & $25.7 \%$ & $85.5 \%$ & $35.0 \%$ & $79.1 \%$ & $69.3 \%$ \\
\hline
\end{tabular}

PPV: positive predictive value; NPV: negative predictive value; ROC: receiver operator characteristics

COPD and underestimate the severity of disease in 41 percent. $^{36}$ When these patients undergo spirometry, physicians change their severity assessments for 30\% of patients and modify treatment in 37 percent. $^{36}$ In addition to smoking cessation, long-acting bronchodilators may reduce the rate of lung function decline, decrease COPD exacerbation and mortality rates, and improve health-related quality of life in individuals with mild to moderate AFO. ${ }^{34}$ Exercise training may increase exercise endurance in patients with mild to moderate COPD. ${ }^{37}$ Thus, diagnosis of AFO may prompt initiation of both pharmacologic and non-pharmacologic treatments which may reduce the morbidity and mortality associated with COPD.

Based upon a systematic review of the benefits and harms of COPD screening, the U.S. Preventive Services Task Force recommends against screening asymptomatic adults for COPD. ${ }^{38}$ However, the World Health Organization statement on the Global Alliance for Respiratory Disorders and the American College of Physicians suggest screening spirometry for at risk or symptomatic individuals. ${ }^{39,40}$ Questionnaires have been advocated for the identification of at risk individuals. The "Screening, Evaluating and Assessing

\section{Figure 2. ROC Curve}

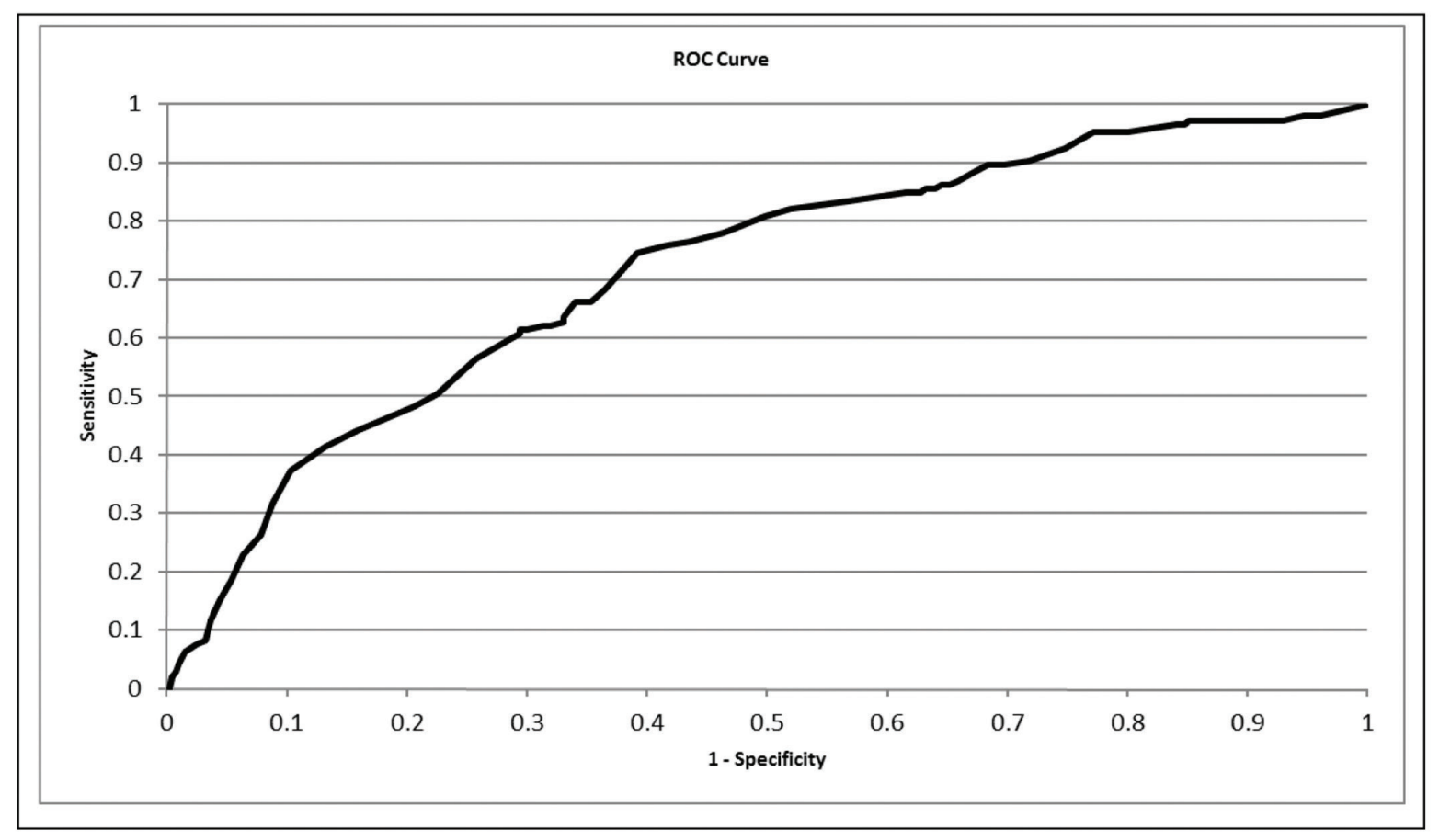

ROC: receiver operating characteristics 
Rate Changes of Diagnosing Respiratory Conditions in Primary Care 1 (SEARCH 1)" study showed that use of the COPD Population Screener alone or with a handheld spirometer significantly increased the COPD diagnostic yield among primary care patients, $0.49 \%$, $1.07 \%$, and $1.16 \%$, control, survey alone, and survey plus spirometer, respectively. ${ }^{41}$ Empiric diagnosis of COPD based upon history and symptoms is often incorrect. Among 3209 Veterans treated empirically for COPD, only $62 \%$ had AFO. Older age, ever smoking, and underweight were associated with AFO whereas congestive heart failure, depression, diabetes, obesity, and sleep apnea were not. ${ }^{42}$

Existing questionnaires for the identification of individuals at risk for AFO have been developed and validated in the general population. However, the VHA patient population is significantly different from the general population. It is older, overwhelmingly male, and has a higher prevalence of smoking and airways obstruction. $^{12}$ For these reasons, a questionnaire designed for a VHA patient population can be expected to have a lower false positive and a higher sensitivity and specificity in this population. Further, prior questionnaires have used a fixed ratio threshold for the definition of AFO; the VAFOSQ is the first screening survey to utilize the LLN threshold for AFO.

A limitation of our study includes the recruitment of participants from VHA primary care clinics. Recruited patients were presenting for an already scheduled primary care clinic visit for general medical problems which might confound the diagnosis of AFO. All patients were offered screening spirometry but patients with respiratory symptoms might be more likely to participate resulting in a higher prevalence of AFO in our cohort than in the general VHA patient population.

The VAFOSQ is a reliable and valid instrument for the identification of veterans at risk for AFO who would benefit from further evaluation with spirometry. The VAFOSQ is straightforward to use and can be easily self-administered and self-scored enabling widespread application throughout the VHA and, perhaps, the Department of Defense.

\section{Acknowledgements}

This work was performed as part of a quality improvement project, "Patient Centered Model for the Management of Chronic Obstructive Pulmonary Disease" funded by Veterans Healthcare Administration Specialty Care Services, Specialty Care Transformation Initiative. Information and data in this manuscript were presented in part at a Poster Symposium at the American Thoracic Society International Conference in 2015. The views and opinions expressed in this article are those of the authors and do not necessarily reflect the official policy or position of any agency of the U.S. government.

\section{Declaration of Interest}

The authors have no relevant interests to declare. 


\section{References}

1. National Institutes of Health, National Heart Lung and Blood Institute. Morbidity \& Mortality: 2012 Chart Book on Cardiovascular, Lung, and Blood Diseases. National Heart Lung and Blood Institute website. http://www.nhlbi.nih.gov/files/ docs/research/2012_ChartBook.pdf. Published 2013. Accessed April 12, 2016.

2. Mathers CD, Loncar D. Projections of global mortality and burden of disease from 2002 to 2030. PLoS Med. 2006;3(11):e442. doi: http://dx.doi.org/10.1371/journal.pmed.0030442

3. Murray CJ, Lopez AD. Alternative projections of mortality and disability by cause 1990-2020: Global Burden of Disease Study. Lancet. 1997;349(9064):1498-1504.

doi: http://dx.doi.org/10.1016/S0140-6736(96)07492-2

4. Mannino DM, Homa DM, Akinbami LJ, Ford ES, Redd SC. Chronic obstructive pulmonary disease surveillance--United States, 1971-2000. Respir Care. 2002;47(10):1184-1199.

5. Miravitlles M, Soriano JB, Garcia-Rio F, et al. Prevalence of COPD in Spain: impact of undiagnosed COPD on quality of life and daily life activities. Thorax. 2009;64(10):863-868. doi: http://dx.doi.org/10.1136/thx.2009.115725

6. Elbehairy AF, Webb KA, Neder JA, O'Donnell DE. Should mild COPD be treated? Evidence for early pharmacological intervention. Drugs. 2013;73(18):1991-2001. doi: http://dx.doi.org/10.1007/s40265-013-0145-9

7. Maltais F, Dennis N, Chan CK. Rationale for earlier treatment in COPD: a systematic review of published literature in mild-tomoderate COPD. COPD. 2013;10(1):79-103. doi: http://dx.doi.org/10.3109/15412555.2012.719048

8. Coxson HO, Leipsic J, Parraga G, Sin Dd. Using pulmonary imaging to move chronic obstructive pulmonary disease beyond $\mathrm{FEV}_{1}$. Am J Respir Crit Care Med. 2014; 190(2): 135-144. doi: http://dx.doi.org/10.1164/rccm.201402-0256PP.

9. Mannino DM, Gagnon RC, Petty TL, Lydick E. Obstructive lung disease and low lung function in adults in the United States: data from the National Health and Nutrition Examination Survey, 1988-1994. Arch Intern Med. 2000;160(11):1683-1689. doi: http://dx.doi.org/10.1001/archinte.160.11.1683

10. Centers for Disease Control and Prevention. Chronic Obstructive Pulmonary Disease Among Adults - United States, 2011. Morbidity and Mortality Weekly Report website. http:// www.cdc.gov/mmwr/preview/mmwrhtml/mm6146a2.htm. Published 2012. Accessed April 11, 2016.

11. Pfizer Pharmaceuticals. Utilization of Veterans Affairs Medical Care Services by United States Veterans, Population Studies Outcomes Research. CiteseerX website. http://citeseerx.ist. psu.edu/viewdoc/download;jsessionid=C2AA907798E6E212B 04BD6FC06451317?doi=10.1.1.389.1296\&rep=rep 1\&type=pdf Published 2003. Accessed April 11, 2016.
12. Murphy DE, Chaudhry Z, Almoosa KF, Panos RJ. High prevalence of chronic obstructive pulmonary disease among veterans in the urban midwest. Military Med. 2011;176(5):552560.

doi: http://dx.doi.org/10.7205/MILMED-D-10-00377

13. Calverley PM, Nordyke RJ, Halbert RJ, Isonaka S, Nonikov D. Development of a population-based screening questionnaire for COPD. COPD. 2005;2(2):225-232. doi: http://dx.doi.org/10.1081/COPD-57594

14. Mullerova H, Wedzicha J, Soriano JB, Vestbo J. Validation of a chronic obstructive pulmonary disease screening questionnaire for population surveys. Respir Med. 2004;98(1):78-83. doi: http://dx.doi.org/10.1016/j.rmed.2003.08.009

15. Barr RG, Herbstman J, Speizer FE, Camargo CA, Jr. Validation of self-reported chronic obstructive pulmonary disease in a cohort study of nurses. Am J Epidemiol. 2002;155(10):965-971. doi: http://dx.doi.org/10.1093/aje/155.10.965

16. Stallberg B, Nokela M, Ehrs PO, Hjemdal P, Jonsson EW. Validation of the clinical COPD Questionnaire (CCQ) in primary care. Health Qual Life Outcomes. 2009;7:26. doi: http://dx.doi.org/10.1186/1477-7525-7-26

17. United States Department of Veterans Affairs. Profile of Veterans: Data from the American Community Survey. 2013; http://www.va.gov/vetdata/docs/SpecialReports/Profile_of Veterans_2011.pdf. Published 2013. Accessed April 11, 2016.

18. Miller MR, Hankinson J, Brusasco V, et al. Standardisation of spirometry. Eur Respir J. 2005;26(2):319-338. doi: http://dx.doi.org/10.1183/09031936.05.00034805

19. Hankinson JL, Odencrantz JR, Fedan KB. Spirometric reference values from a sample of the general U.S. population. Am J Respir Crit Care Med. 1999;159(1):179-187.

doi: http://dx.doi.org/10.1164/ajrccm.159.1.9712108

20. Global initiative for hronic Obstructive Lung Disease (GOLD). Global Strategy for Diagnosis, Management, and Prevention of COPD. GOLD website. http://www.goldcopd.org/uploads/ users/files/WatermarkedGlobal\%20Strategy\%202016(1).pdf. Published January 2014. Accessed April 11, 2016.

21. Vollmer WM, Gislason T, Burney P, et al. Comparison of spirometry criteria for the diagnosis of COPD: results from the BOLD study. Eur Respir J. 2009;34(3):588-597.

doi: http://dx.doi.org/10.1183/09031936.00164608

22. Hanley JA, McNeil BJ. The meaning and use of the area under a receiver operating characteristic (ROC) curve. Radiology. 1982;143(1):29-36.

doi: http://dx.doi.org/10.1148/radiology.143.1.7063747

23. Habraken JM, Pols J, Bindels PJ, Willems DL. The silence of patients with end-stage COPD: a qualitative study. $\mathrm{Br} J \mathrm{Gen}$ Pract. 2008;58(557):844-849.

doi: http://dx.doi.org/10.3399/bjgp08X376186 
24. Carlone S, Balbi B, Bezzi M, et al. Health and social impacts of COPD and the problem of under-diagnosis. Multidiscip Respir Med. 2014;9(1):63. doi: http://dx.doi.org/10.1186/2049-6958-9-63

25. Miravitlles M, de la Roza C, Morera J, et al. Chronic respiratory symptoms, spirometry and knowledge of COPD among general population. Respir Med. 2006;100(11):1973-1980. doi: http://dx.doi.org/10.1016/j.rmed.2006.02.024

26. Shahab L, Jarvis MJ, Britton J, West R. Prevalence, diagnosis and relation to tobacco dependence of chronic obstructive pulmonary disease in a nationally representative population sample. Thorax. 2006;61(12):1043-1047. doi: http://dx.doi.org/10.1136/thx.2006.064410

27. Caramori G, Bettoncelli G, Tosatto R, et al. Underuse of spirometry by general practitioners for the diagnosis of COPD in Italy. Monaldi Arch Chest Dis. 2005;63(1):6-12. doi: http://dx.doi.org/10.4081/monaldi.2005.651

28. Soriano JB, Zielinski J, Price D. Screening for and early detection of chronic obstructive pulmonary disease. Lancet. 2009;374(9691):721-732.

doi: http://dx.doi.org/10.1016/S0140-6736(09)61290-3

29. Ferguson GT, Enright PL, Buist AS, Higgins MW. Office spirometry for lung health assessment in adults: A consensus statement from the National Lung Health Education Program. Chest. 2000;117(4):1146-1161.

doi: http://dx.doi.org/10.1378/chest.117.4.1146

30. Welte T, Vogelmeier C, Papi A. COPD: early diagnosis and treatment to slow disease progression. Int $J$ Clin Pract. 2015;69(3):336-349. doi: http://dx.doi.org/10.1111/ijcp.12522

31. Balcells E, Gimeno-Santos E, de Batlle J, et al. Characterisation and prognosis of undiagnosed chronic obstructive pulmonary disease patients at their first hospitalisation. BMC Pulm Med. 2015;15(4).

doi: http://dx.doi.org/10.1186/1471-2466-15-4

32. Parkes G, Greenhalgh T, Griffin M, Dent R. Effect on smoking quit rate of telling patients their lung age: the Step2quit randomised controlled trial. BMJ. 2008;336:598-600. doi: http://dx.doi.org/10.1136/bmj.39503.582396.25

33. Bednarek M, Gorecka D, Wielgomas J, et al. Smokers with airway obstruction are more likely to quit smoking. Thorax. 2006;61(10):869-873.

doi: http://dx.doi.org/10.1136/thx.2006.059071

34. Scanlon PD, Connett JE, Waller LA, et al. Smoking cessation and lung function in mild-to-moderate chronic obstructive pulmonary disease. The Lung Health Study. Am J Respir Crit Care Med. 2000;161(2 Pt 1):381-390.

doi: http://dx.doi.org/10.1164/ajrcem.161.2.9901044
35. Fletcher C, Peto R. The natural history of chronic airflow obstruction. Br Med J. 1977;1(6077):1645-1648. doi: http://dx.doi.org/10.1136/bmj.1.6077.1645

36. Mapel DW, Dalal AA, Johnson P, Becker L, Hunter AG. A clinical study of COPD severity assessment by primary care physicians and their patients compared with spirometry. Am J Med. 2015;128(6):629-637. doi: http://dx.doi.org/10.1016/j.amjmed.2014.12.018

37. O'Donnell DE, Gebke KB. Examining the role of activity, exercise, and pharmacology in mild COPD. Postgrad Med. 2014;126(5):135-145.

doi: http://dx.doi.org/10.3810/pgm.2014.09.2808

38. U.S Preventive Services Task Force. Screening for chronic obstructive pulmonary disease using spirometry: U.S. Preventive Services Task Force recommendation statement. Ann Internal Med. 2008;148(7):529-534.

doi: http://dx.doi.org/10.7326/0003-4819-148-7-200804010-00212

39. World Health Organization. Global surveillance, prevention and control of CHRONIC RESPIRATORY DISEASES: A comprehensive approach. 2020. World Health Organization website. http://www.who.int/gard/publications/GARD\%20Book \%202007.pdf?ua=1.Published 2007. Accessed April 11, 2016.

40. Qaseem A, Wilt TJ, Weinberger SE, et al. Diagnosis and management of stable chronic obstructive pulmonary disease: a clinical practice guideline update from the American College of Physicians, American College of Chest Physicians, American Thoracic Society, and European Respiratory Society. Ann Intern Med. 2011;155(3):179-191. doi: http://dx.doi.org/10.7326/00034819-155-3-201108020-00008

41. Yawn BP, Duvall K, Peabody J, et al. The impact of screening tools on diagnosis of chronic obstructive pulmonary disease in primary care. Am J Prev Med. 2014;47(5):563-575. doi: http://dx.doi.org/10.1016/j.amepre.2014.07.030

42. Collins BF, Feemster LC, Rinne ST, Au DH. Factors predictive of airflow obstruction among veterans with presumed empirical diagnosis and treatment of COPD. Chest. 2015;147(2):369-376. doi: http://dx.doi.org/10.1378/chest.14-0672 